Rhode Island College

Digital Commons @ RIC

$5-1-2013$

\title{
Mandatory Influenza Vaccination for Healthcare Workers: Do Nurses Agree?
}

Meghan Leah Nightingale

Rhode Island College

Follow this and additional works at: https://digitalcommons.ric.edu/etd

Part of the Nursing Commons

\section{Recommended Citation}

Nightingale, Meghan Leah, "Mandatory Influenza Vaccination for Healthcare Workers: Do Nurses Agree?" (2013). Master's Theses, Dissertations, Graduate Research and Major Papers Overview. 221.

https://digitalcommons.ric.edu/etd/221

This Major Paper is brought to you for free and open access by the Master's Theses, Dissertations, Graduate Research and Major Papers at Digital Commons @ RIC. It has been accepted for inclusion in Master's Theses, Dissertations, Graduate Research and Major Papers Overview by an authorized administrator of Digital Commons @ RIC. For more information, please contact digitalcommons@ric.edu. 
Running Head: MANDATORY INFLUENZA VACCINATION

\title{
MANDATORY INFLUENZA VACCINATION
}

FOR HEALTHCARE WORKERS: DO NURSES AGREE?

by

\author{
Meghan Leah Nightingale \\ A Major Paper Submitted in Partial Fulfillment \\ of the Requirements for the Degree of \\ Master of Science in Nursing \\ in \\ The School of Nursing \\ Rhode Island College
}

2013 


\title{
MANDATORY INFLUENZA VACCINATION
}

\author{
Abstract \\ Influenza is a significant cause of morbidity and mortality among hospitalized patients. \\ Health care workers are considered a high-risk group for influenza, and annual \\ vaccination is the most effective way to prevent getting influenza. Increasing concern \\ about inadequate levels of healthcare work vaccination has led many groups to \\ recommend mandatory vaccination for healthcare workers. The state of Rhode Island was \\ considering mandatory vaccination in 2012 for all healthcare workers, with only medical \\ exemption, but this movement was halted. Research focused on the perception of nursing \\ personnel toward mandatory influenza vaccination is lacking, and considering that \\ registered nurses are one of the largest healthcare groups that would be affected, this is an \\ area of concern. The purpose of this research study was to examine the perception of \\ nursing staff toward mandated vaccination at a hospital in Rhode Island. The survey used \\ a mixed methods design, including forced choice questions and an open-ended question, \\ developed for purposes of this research. The study participants included RNs employed \\ in inpatient units. Most of the nurses disagreed that healthcare workers should be \\ mandated to get immunization and disagreed that a vaccine policy requiring mandatory \\ vaccination was fair. They also disagreed that hospital policy requiring influenza \\ vaccination keeps them from getting influenza or keeps their patients from getting \\ influenza. In one of the first states considering mandatory vaccination statewide, these \\ results are an important consideration before implementation of this potential measure. \\ Keywords: mandatory influenza vaccination, nursing perception
}




\section{MANDATORY INFLUENZA VACCINATION}

\section{Table of Contents}

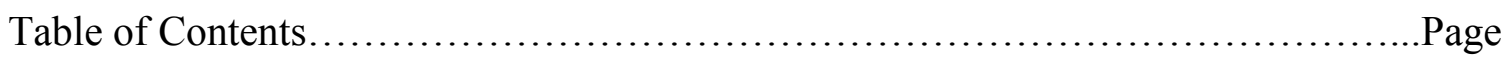

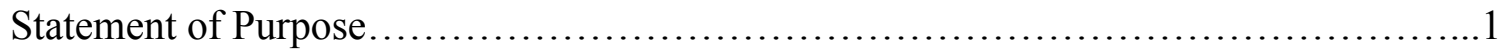

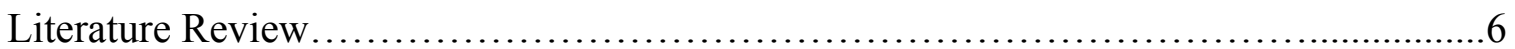

Theoretical Framework........................................................... 19

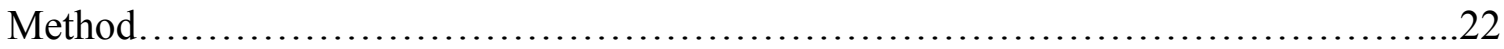

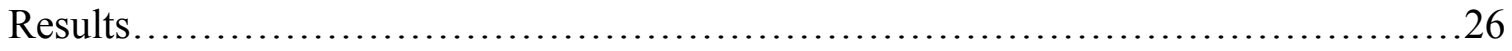

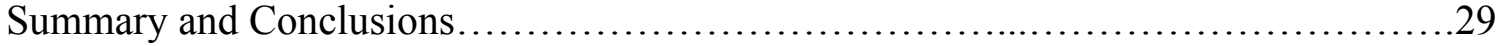

Recommendations and Implications for Advanced Nursing Practice....................34

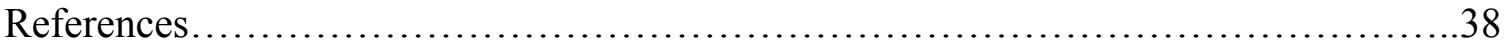

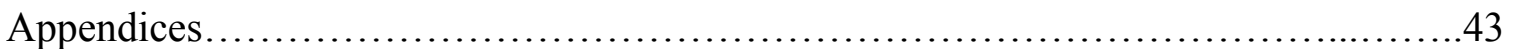


Mandatory Influenza Vaccination for Healthcare Workers:

Do Nurses Agree?

\section{Problem Statement and Background}

Influenza is a significant cause of morbidity and mortality among hospitalized patients. Annual influenza vaccination is the most effective way to prevent getting influenza (Centers for Disease Control [CDC], 2011). It can prevent people from becoming ill and may decrease morbidity and mortality among people at high risk for complications. Estimates of flu-related deaths in the United States (US) over the past 40 years have been as high as 49,000 per year, with the majority of deaths occurring in people aged 65 years and older (CDC). More than 200,000 people are hospitalized for

respiratory illness and heart conditions associated with seasonal influenza (The National Vaccine Advisory Committee, 2012).

Most healthy adults are able to infect others with the influenza virus from one day prior to the development of symptoms until almost a week after symptoms resolve (CDC, 2011). Flu viruses are constantly changing, and immunity decreases over time, which is why vaccination is recommended on an annual basis. Currently, the most common form of influenza vaccination is an injection, which contains non-infectious, inactivated viruses, but cannot cause the flu. Since 2003, a live attenuated vaccine has been approved for intranasal use in certain populations. This vaccine has a weakened form of the virus that also cannot cause the flu. Overall, serious side effects of the flu vaccine have been reduced over the years through improvements through manufacturing and currently, the most common side effect is mild soreness at the injection site, lasting one to two days. 
The vaccine is considered to be both safe and effective (U. S. Department of Health \& Human Services [U.S. DHHS], 2012).

The National Vaccine Advisory Committee recommends that all people over the age of six months receive annual vaccination (2012). Healthcare workers are considered a high-risk group due to caring for patients at high-risk for developing flu related complications. Since 1981, the CDC has recommended annual influenza vaccination among healthcare workers (2011). Vaccination of all health care personnel is a specific focus of recommendation by the U.S. DHHS and other public health agencies and professional organizations. Health care provider vaccination rates vary annually, but are consistently below the Healthy People 2020 goal of achieving a 90\% immunization rate (U.S. DHHS, 2012). During the 2010-2011 influenza season, which included October until May, coverage for influenza vaccination among healthcare workers was estimated at $63.5 \%$. Coverage was $98.1 \%$ among health care workers who had an employer requirement for vaccination (CDC, 2011).

Low rates of healthcare worker vaccination increase the risk for influenza outbreaks in the healthcare setting. Herd immunity describes the process of vaccinating a certain percentage of a population, thereby preventing vulnerable people, including immune-compromised and other susceptible patients, from getting influenza. Without adequate levels of vaccination, herd immunity is decreased in the hospital. Low rates of healthcare worker vaccination increase staff illness and absenteeism and influenza related illness and death (CDC, 2011). Therefore, vaccination directly protects healthcare workers and indirectly protects patients. 
Growing concern among government institutions and infectious disease organizations has led to consideration of mandating vaccination among healthcare workers. Although the autonomy of healthcare workers must be respected and considered, the government has an obligation to protect the public. Currently, most employers view immunization as a personal choice of employees and thus employees may choose to refuse treatment. However, healthcare workers are also familiar with the concept of non-maleficence, an obligation to avoid inflicting harm to patients. Patients expect that providers take reasonable precautions to prevent nosocomial or hospital acquired illness. Because of the risk, there is a shift toward recognizing influenza immunization as a patient health and safety initiative.

Some specific interventions that have been implemented to improve vaccination rates include offering vaccines on-site, free of charge, for multiple days and shifts (CDC, 2011). Educational programs, mandatory signed declination forms, and yearly campaigns, including mobile vaccination carts, have also been used. For those who choose not to be vaccinated, mandatory protective equipment (face mask) for staff within a certain distance from patients has also been attempted in various institutions. Despite multiple interventions, rates of healthcare provider immunization remain low nationwide.

Many significant organizations support mandatory influenza vaccination for healthcare workers. These include the Infectious Disease Society of America, The American Academy of Pediatrics, the American College of Physicians, the American Medical Directors Association, the American Public Health Association, the Association for Professionals in Infection Control and Epidemiology, the Infectious Diseases Society 
of America, the National Foundation for Infectious Diseases, the National Patient Safety Foundation, and the Society for Healthcare Epidemiology of America (Immunization Action Coalition, 2012). The Joint Commission (TJC) is a non-profit agency viewed as driver of quality and safety that accredits and certifies health care organizations, such as hospitals. Beginning in 2007, TJC began to require influenza vaccination programs for maintaining accreditation. Programs must include on site vaccination, staff education, and declination statements, or documented reasons for refusal (TJC, 2006).

The American Nurses Association (ANA), a professional organization that claims to represent the interests of the nation's registered nurses, advocates that nurses obtain influenza vaccination annually. However, it cautions that nurses' rights must be protected and nurses must be treated fairly and without discrimination. ANA has determined that they will only support mandatory influenza vaccination if it comes from the highest level of legal authority (such as state government), if suitable exemptions such as allergy are included, and if discriminating against or punishing nurses who do not participate is prohibited (ANA, 2010). It would seem that without endorsing support to penalize those who disobey a mandatory policy, the ANA truly does not support mandating vaccination. Lifespan Corporation is currently the largest healthcare group in Rhode Island. According to Donna Dube, Director of Lifespan Employee and Occupational Health Services in 2012, (personal communication, May 30, 2012), and Nancy Vallande (personal communication, May 29, 2012), Director of Infection Control at The Miriam Hospital, one of hospitals in the Lifespan group Rhode Island (RI) was strongly considering mandatory influenza vaccination for Fall 2012 for all healthcare workers. RI 
would have been the first state to mandate statewide. At the end of the summer, 2012, this measure ultimately did not pass at the state level. Lifespan Corporation followed state minimum requirements, allowing medical exemption or documented reason for refusal as the only ways to opt out of vaccination. During the period of flu epidemic in the winter of 2012-2013, the RI Department of Health (RI DOH) required mask wearing for all unvaccinated healthcare workers with direct patient contact (RI DOH, 2012). Given that mandatory vaccination was a consideration during the 2012 flu season, and Lifespan has revised its vaccination protocol to promote increased influenza vaccination over the past several years, mandatory vaccination may become a reality in the near future in RI. Research about whether or not nursing personnel agree with and will support this mandate is limited. In a state that has never mandated influenza vaccination before, it is important to know the barriers, fears, and opinions from registered nurses, both to defray litigation and to gain the support of staff. The purpose of this project was to examine the perception of nursing staff toward mandated vaccine at a hospital in RI. 


\section{Review of the Literature}

A comprehensive assessment of relevant literature was conducted, using both CINAHL and Medline (Ovid) databases. Keywords used included influenza vaccination, mandate, nurses, healthcare workers, healthcare personnel, and mandatory vaccination. The time frame for the search was January 2006 to January 2013. Articles written in languages other than English were excluded. Epidemiological data was retrieved from US regulatory agencies and professional organizations, including the CDC, TJC, USDHHS and ANA.

\section{History of Vaccination and Relation to Influenza}

Protection from viruses depends on having been exposed to viruses before, through infection or vaccine for that virus. The immune system remembers the virus and creates antibodies that will prevent the virus from causing infection once it enters the body. The history of vaccination begins with evidence that China used smallpox inoculation to prevent the disease as early as $1000 \mathrm{AD}$. This idea spread to Africa and Turkey before making the way to both Europe and the US. In 1976, Edward Jenner began using cowpox material to create immunity to smallpox. His method underwent medical and technological changes over the next 200 years and ultimately eradicated smallpox. Rabies vaccine followed in 1885, and antitoxins and vaccines against diphtheria, tetanus, anthrax, cholera, plague, typhoid, and tuberculosis were developed in the 1930s (The College of Physicians of Philadelphia, 2013).

The $20^{\text {th }}$ century was an active time for vaccine research and development. Methods for growing viruses in the laboratory led to various new innovations and 
discoveries, including vaccines for many childhood diseases. While the name "influenza" originated in $15^{\text {th }}$ century Italy, the influenza A virus was isolated in 1933, and influenza B in 1936. It was quickly realized that influenza virus could be grown in embryonated hens' eggs, which led to the development of inactivated vaccines in the 1950s. The first live attenuated virus vaccine was licensed in 2003. Currently vaccine creation is refined and even more innovative. Examples include using recombinant DNA technology and new delivery techniques (The College of Physicians of Philadelphia, 2013).

In the US, policies mandate certain immunizations, such as those required for school entry. Ethical objections to these directives began because some individuals or groups disagreed with the mandates based on religious or philosophical beliefs (The College of Physicians of Philadelphia, 2013). The influenza vaccine is just one of many vaccines which has been debated over time.

\section{Barriers against Vaccination and Motivators for Vaccination}

One group of studies examined barriers and motivators toward vaccination. These studies did not necessarily look at mandatory vaccination. In a cross-sectional survey conducted in 2005 at two tertiary care hospitals in Pittsburgh (Christini, Shutt, \& Byers, 2007), the authors sought to determine vaccination rates and motivators among health care worker groups during the 2005-2006 season. A total of 1,042 surveys were completed, resulting in a $42 \%$ response rate. Sixty nine percent of physicians and $63 \%$ of medical students were vaccinated, as opposed to $46 \%$ of nurses. The authors concluded that groups with the greatest amount of patient contact, including nurses and nursing aides, were not adequately vaccinated. The most common reported reason for rejecting 
vaccination among nurses was vaccine shortage, followed by concern about side effects. This study also looked at attitudes toward vaccination. Almost half of those surveyed (46\%) believed that vaccination should be mandatory, 39\% did not, and $16 \%$ percent were not sure. Unfortunately, this question was not separated among care groups, so the opinions of nurses were not isolated and explored. As in most of these studies, data was derived from self-reported data.

On the other hand, a qualitative, cross sectional study reported reasons for accepting the vaccine utilizing a vaccine questionnaire of healthcare workers (Rebmann, Wright, Anthony, Knaup, \& Peters, 2012). The site was in Saint Louis, and included 69 hospital and non-hospital settings. A total of 3,188 healthcare workers completed the survey. Hospital based healthcare workers were more likely to be offered the vaccine free and on-site. Hospital providers were much more likely to report receiving vaccine than non-hospital workers. For those that reported a mandatory vaccine policy at their institution, $63 \%$ reported it was not enforced. After controlling for demographics and past behavior, determinants of hospital workers obtaining influenza vaccination included having a mandatory vaccination policy, belief that healthcare workers should be vaccinated yearly, occupational health encouragement, perceived importance of vaccination, on-site access, and no fear of vaccine adverse effects. While non-hospital workers had different motivators, the strongest predictor was a mandatory vaccination policy. A limitation to this study was that a mandatory, enforced policy was not specific, and could mean that staff members were fired for noncompliance, required to wear a mask, required to attend a counseling session, or had paychecks withheld. This study also 
did not address staff attitudes toward a mandatory policy.

Toronto and Mullaney (2010) reviewed literature published between 2003 and 2009 exploring nurses' decision making about influenza vaccination. Twelve research articles were reviewed, using the criteria that articles needed to be published research in peer-reviewed journals. Studies reviewed ranged from a sample size of only 11 nurses from a province of Nova Scotia to as many as 1,017 nurses from four states. Three of the 12 research articles were published in nursing journals, eight in medical journals, and one in a health economics journal. Research came from several countries, including the U.S., U.K., Canada, Israel, Greece and Brazil. Nine of the 12 were quantitative designs, the others qualitative. The authors found that nurses who declined the vaccine did not feel personally at risk for influenza: between $19 \%$ and $29 \%$ of staff nurses surveyed in health care agencies in the various studies felt they were not at risk. Concerns about the vaccine's safety and efficacy were major barriers, followed by lack of knowledge, time constraints and avoidance of injections. The strongest reasons for obtaining the vaccine included protection from influenza. Unfortunately, the inclusion criteria also included a theoretical basis, which may have excluded some relevant research. The authors noted that more research specifically focused on nursing was needed.

One cross sectional study examined nurses' influences on decision making about vaccination (Daugherty, Speck, Rand, \& Perl, 2011). Nine hundred and twenty eight hospital staff at a tertiary hospital in Baltimore were surveyed during 2008-2009, and $75 \%$ responded. Staff included physicians, nurses, students, and administrative staff, among others. Questions about the current influenza vaccine policy were asked, and 42\% 
of respondents were unfamiliar with recent changes. Significant differences were noted in vaccination rates by role and race. Nurses and physicians were much more likely to be vaccinated than environmental or administrative staff. Specific to race, significantly lower vaccination rates were found among African Americans, but no differences were noted on the basis of sex or age. Those who reported consistent annual vaccination were more likely to believe that the vaccine protected them against flu and prevented the spread of flu. Those who reported inconsistent yearly vaccination stated that extrinsic factors, such as mask requirement or supervisor expectations, influenced their decision. Attitudes toward hospital vaccination policy were also examined, and again, significant differences between the two groups were found. Those who reported inconsistent vaccination were more likely to describe the policy as unfair, and less likely to believe that the policy impacted the spread of influenza. It seemed obvious that staff with a history of inconsistent vaccination would have unstable motivators for getting the vaccine. The new policy in this study, however, did not subject staff to any specific discipline for failing to receive the vaccine or wearing a mask. Like many others, this study was limited in that it was implemented in only one institution.

\section{Vaccination Rate Response to Interventions}

Some studies have examined the response to various interventions implemented to increase vaccination. Many of these interventions were based on eliminating the barriers previously identified in this review.

One study examined vaccination rates among 22 hospitals in the U.S. prior to and after implementation of declination statements (Polgreen et al., 2008). This study was a 
secondary data analysis, in which the authors examined vaccination rates in hospitals that had implemented forced vaccination declination statements as a measure to increase vaccination rates in these facilities. A statistically significant mean increase in vaccination rates of $11.6 \%(\mathrm{p}<0.001)$ was seen in these institutions. Declination programs were considered mandatory, but at most facilities, no penalties were imposed if an individual refused to sign. While these numbers are impressive, the exact impact of these forms was unclear, as other strategies were implemented at the same time to increase vaccination rates.

Ribner et al. (2008) evaluated the effectiveness of using a declination form during the 2006-2007 influenza season in three hospitals, one skilled nursing facility, and an administrative building. A total number of 9214 non-physician employees were employed. In these healthcare facilities, $66.5 \%$ of employees received influenza vaccination, compared with $43 \%$ during the prior influenza season without a declination form. When analyzed by subgroup, nurses were more likely to accept vaccination than all others combined, including pharmacy. Reasons for declination were also analyzed by subgroup, including nurse, pharmacy ancillary personnel, and other employees. A common reason for nurse declination was fear of adverse effects, followed by "I never get the flu." Again, implementing the declination form was one of several measures implemented during that season, so the exact influence of declination forms was unknown.

In a randomized trial of 344 staff members in Jerusalem, Israel during the 20072008 season, a promotional and educational intervention program was instituted 
(Abramson, Avni, Levi, \& Miskin, 2010). These staff members all had direct patient contact in primary care clinics. Thirteen clinics were randomly selected to participate in an intervention to increase low immunization rates among healthcare workers. The intervention included lectures to convey vaccine information and educational materials by email. The immunization rate increased $25.8 \%$ over the rate reported for the prior season. Multivariate analysis showed a highly significant independent association between intervention and immunization $(\mathrm{p}<0.001)$. This study, like most of the others, did not focus solely on nurses. It also focused on primary care settings, which was not the setting of interest for this study.

Cadena et al. (2011) examined various quality improvement influenza initiatives implemented at a 498-bed university-affiliated health system. A retrospective data analysis was completed to compare vaccination rates before and after intervention. The intervention included leadership support, an influenza website, a screen saver, emails, phone messages, audit feedback and a declination form with rationale. The vaccination rate increased from $58.8 \%$ in 2008 to $76.6 \%$ in 2009 , which was statistically significant $(p<0.01)$. However, the author conceded that the widely publicized severity and consequences of the $2009 \mathrm{H} 1 \mathrm{~N} 1$ virus likely contributed to the increased vaccination rate. As in the other studies, reasons for declination were analyzed, and included concerns about getting influenza, concerns about side effects and doubt about effectiveness. The author conceded that mandatory vaccination may be likely to reach desired vaccination levels of $>80 \%$.

A retrospective data analysis was completed using six years of influenza 
vaccination data at Kelsey-Seybold Clinic in Houston, Texas (Mouzoon et al., 2011). Several separate strategies were implemented for pregnant women and healthcare workers. For healthcare workers, an employee survey about influenza knowledge was conducted, and education was provided based on the survey results and CDC recommendations. Vaccines were made readily available and free of charge, immunization nurses were designated as clinical champions, and influenza vaccination rates were monitored and reported. Finally, the clinic with the highest rate was recognized. Employee influenza vaccination rates in this study were found to increase dramatically over the six years studied, from $36 \%$ to $64 \%$.

Researchers conducted a long-term data analysis of facility vaccination rates at a national single- payer hospital system with 153 hospitals (Hirsch, Hodgson, \& Davey, 2011). The site for this study was hospitals affiliated with the Veterans Health Administration, which since 2004 had implemented a systematic information campaign to provide staff responsible for vaccination with support. Each year, national-level plans were revised based on feedback from the prior year, and a vaccine coordinator was appointed as a designated champion to provide feedback. A web-based questionnaire and semi-structured interviews were conducted with influenza coordinators to identify reasons for success and failure. Facilities were separated based on complexity, which included patient population, clinical services complexity, and education and research. Each facility implemented the new strategies somewhat differently.

Vaccination rates increased from $45 \%$ in $2005-2006$ to $66.5 \%$ in $2008-2009$ $(p<0.05)$. Based on the survey results, no individual factor was associated with higher 
vaccination rates. Interestingly, vaccine shortages, number of locations in which the vaccine was offered, number of educational interventions or specific techniques, and increased publicity did not change the vaccination rate. Unlike other studies, use of mandatory declination statements also did not affect the vaccination rate. Higher vaccination rates were associated with decreased facility complexity.

\section{Results of Mandatory Vaccination Policies}

Rakita, Hagar, Crome, \& Lammert (2010) examined the results of a mandatory vaccination program instituted in 2005 at Virginia Mason Medical Center in Seattle, Washington. Unlike that proposed in RI, these facilities had individual, not statewide, employer requirements. Virginia Mason Medical Center is a tertiary care medical center that includes a 336 bed teaching hospital and outpatient clinics. Employees were exempted based on medical or religious reasons, and were required to wear a mask at work during influenza season if exempt. A workshop was held to generate ideas to increase influenza vaccination, and mandatory vaccination was recommended and approved. Multiple delivery methods were used, including training peers to administer vaccines, using mobile flu carts, and extending hours of operation for employee health. Employees were allowed to receive vaccination elsewhere as long as evidence was provided. Employees with a history of egg allergy or reaction to the vaccine underwent skin testing for proof of allergy. Multiple types of vaccine were available, including thimerosal- free killed live virus, thimerosal- preserved killed virus, and live, attenuated nasal vaccine. The main outcome of this study was that the rate of vaccination among healthcare workers increased from $54 \%$ in 2003 to $97.6 \%$ in 2006 , with almost 5,000 
healthcare workers vaccinated that year.

A small number of healthcare workers refused to be vaccinated. Five voluntarily left their positions, and two were terminated in 2006. Since then, a total of two healthcare workers have left as a result of the influenza vaccination requirement. When the fitnessfor-duty requirement of vaccination was adopted, the Washington State Nurses Association filed a grievance on behalf of unionized workers, based on the requirement that any changes had to be negotiated through their collective bargaining agreement. An arbitrator found in their favor, and unionized, inpatient nurses did not have to be vaccinated, though most unionized nurses $(95.8 \%)$ still elected to do so. This study showed the effectiveness of mandatory influenza vaccination, but also the ethical dilemma and complications involved with such a requirement.

A follow-up commentary article provided further insight about the effects of the mandate (Talbot \& Schaffner, 2010). Apparently, employee sick leave in January and February did not decrease significantly after the new program began. The effect of immunization on patient influenza infection was not evaluated. In addition, the commentary described that the program cost a significant sum of money, including costs spent in litigation with the Washington State Nurses Association. Additional cost is likely and should be anticipated when facing the challenge of such a new mandate. Perhaps assessing nurses concerns prior to and during implementation of a mandatory policy could defray or reduce such litigation. Interestingly, the authors reported that staff satisfaction actually increased after the institution of the new vaccination requirements, although this could not be directly attributed to the new policy. 


\section{Perception of Mandatory Influenza Vaccination}

A final group of studies investigated nurses' perception of the mandate. However, in these studies, the mandate was a concept, not a reality, which may have skewed opinions. In a mixed methods descriptive study, 14 semi-structured interviews were completed with registered nurses (RNs) (Rhudy, Tucker, Ofstead, \& Poland, 2010). The RNs were chosen based on their indication from a prior survey that they were uncertain about or would not receive an influenza vaccine the next season. This study was unique in that it focused only on nurses: both qualitative and quantitative interview questions were included. As supported in prior studies, influenza immunization was seen as a low priority for nurses, and nurses were skeptical of the value of the vaccine. Nurses reported being fearful of side effects, and viewed vaccination as a personal health choice, not a patient safety measure. One of the interview questions asked about the idea of making influenza vaccination mandatory. Most nurses said they would comply with mandatory vaccination, although not in favor of this option. This finding was not surprising, since these were nurses who were not sure or would not get vaccinated. The small sample size was identified as a limitation, but the study supported the idea that most nurses would accept vaccination if mandated.

Poland, Ofstead, Tucker, \& Beebe (2008) researched preferred methods of influenza prevention and whether nurses would support a policy of mandatory vaccination for healthcare workers with informed declination. Nurses employed at Mayo Clinic ( $\mathrm{n}=513$ ) were surveyed using a cross sectional method, and more than half of the respondents favored receiving influenza immunization as prevention. Approximately 
$59 \%$ reported that they would support a policy that required annual influenza vaccination with medical or religious exemption, or informed declination. An association was detected between past receipt of influenza vaccination and opinions about mandatory vaccination. Specifically, $65.3 \%$ of nurses who had received influenza vaccination in the past supported mandatory vaccination. Not surprisingly, only $20.6 \%$ of nurses who had never been vaccinated before supported mandatory vaccination $(p<0.001)$. This study was relevant because it studied only nurses. However, mandated influenza vaccination permitted declination for any reason, which was then no different than the previous influenza policies in many institutions. This does not truly represent mandatory vaccination.

Healthcare workers from a 317-bed children's hospital were surveyed in a crosssectional design regarding knowledge and attitudes regarding influenza immunization (Myers, Lantos, Douville, \& Jackson, 2010). Physicians, nurses, and other employees were included in this sample of 585, but replies were examined separately. Knowledge about the vaccine was tested, along with support for mandatory vaccination for influenza for healthcare workers and for childhood vaccines. Most nurses (70\%) agreed that the hospital should mandate influenza vaccination, unless there was a medical reason $(\mathrm{p}=$ $0.019)$. Other employees were more likely than nurses $(p=0.026)$ to agree that they would quit their job rather than comply with mandatory vaccination. This study focused on the originally proposed type of mandate for RI, allowing only medical exemption. However, as in the other studies, employees were surveyed on a proposed mandate, and likely, if the mandate were a reality, opinions would be different. 


\section{Critique of Literature}

In summary, while there are some commonalities in findings, many limitations exist. Most of the research conducted to date provides relatively weak evidence, since findings are derived from self-reported surveys, interviews, quality improvement projects, and pilot projects. Overall, sample sizes were small, were often conducted at one institution, and multiple methods and varying methods were implemented with little control, making interpretation difficult. Both barriers to voluntary vaccination and results of mandatory policies have been well described, and the available evidence suggested that voluntary vaccination programs have failed to achieve desirable rates of health care worker influenza vaccination. While recent improvements have been made, the rates are not at levels recommended by Healthy People 2020 (U.S. DHHS, 2012). In addition, much of the research categorizes nurses with other disciplines, including administration and physicians. Clearly, further research specific to nurses is indicated.

Next, the theoretical framework that guided this study will be presented. 


\section{Theoretical Framework}

Since the focus of the study was on nurses' perception of mandatory vaccination, the Social Ecological Model of Health was chosen as a relevant framework to guide the research. The Social Ecological Model of Health is based on a broad theme combining several fields of research. Urie Bronfenbrenner originally proposed an ecological model over 30 years ago (Bronfenbrenner, 1979). His model suggested reciprocal causation between the individual and the environment, delineating environmental influences into various levels, including micro, meso, exo and macro. The most important concept was that the individual and the environment interact with and influence one another. Environmental conditions may affect people differently, depending on factors at each of the various levels.

A variation on the ecological model relates the theory toward health promotion, and has been used by the CDC to describe both prevention of violence and colorectal cancer (CDC, 2009). It focuses attention on individual and environmental factors as targets for interventions, and can be related to vaccination as prevention against influenza. This social ecological model for health suggests that interventions may be more effective when environments conducive to risk reduction are created (McLeroy, Bibeau, Steckler, \& Glanz, 1988). Individuals are not solely responsible for making choices that reduce risk. A change of environment is also necessary.

Variables at each level of the social ecological model of health can be seen as significant predictors of intent to get vaccinated, and interventions should target multiple levels of the framework for best results. The levels in the revised model are titled slightly 
differently than Bronfenbrenner's original model, and include intrapersonal, interpersonal, organizational, community, and public policy (McLeroy et al., 1988). The first category identifies intrapersonal factors, including knowledge, attitudes, and intention to comply with vaccination. This level was targeted in the various interventions to increase the influenza rate uncovered in the literature review, such as educational programs and media. Most of the studies focusing on barriers and knowledge surveys would fall into this category. Interpersonal relationships must also be considered, including social networks, family, friends, coworkers, and others who may influence the decision. These relationships serve as influences in the decision for vaccination.

Organizational factors focuses on the hospital, the place of employment for the nurses. The hospital serves both to transmit values and to build support for behavior change through leadership. Other organizational factors at play include the lack of cost for the vaccine, the use of mobile vaccination carts, and flexible vaccination hours. Declination statements and other factors in the intervention section serve as organizational factors that may increase rates.

Community factors include groups to which an individual can belong, including extended family, church, informal social networks, and neighborhoods. As described in the background section, there are many influential organizations in support of mandatory vaccination. Organizations may have positive and negative effects on the health of the members. The ANA has not released a statement currently in favor of mandatory vaccination, and may serve as a major group to which many nurses belong.

Finally, public policy includes regulatory policies, procedures, and laws that have 
been passed to help protect the health of communities. This would include the potential for mandated influenza vaccination among healthcare workers in RI, as well. This would also include hospital policy, such as any punitive measures put in place to enforce the policy. The ecological model of health explains that this element must be in place for vaccination rate success, and it appears that this often has been lacking based on the literature review. The level of compatibility between people and their surroundings can be viewed as a predictor of health in social ecological research (Stokols, 1995). As the literature review described, the compatibility between nursing staff and mandatory vaccination has not been comprehensively assessed.

Next, study methods will be presented. 


\section{Methodology}

\section{Purpose/ Research Question}

The purpose of this study was to examine the perception of nursing staff toward mandatory influenza vaccination at a hospital in RI.

The research question was "What is the perception of registered nurses (RNs) at The Miriam Hospital (TMH) toward the mandate of seasonal influenza vaccination?" The outcome variable measured was nurses' perception, based on survey results.

\section{Type of Design}

The survey used a mixed methods design, including forced choice questions, as well as an open-ended question, developed for purposes of this research.

\section{Sample}

The study participants included RNs employed in inpatient units at $\mathrm{TMH}$, regardless of shift, hours worked, or care area. Participants were from any inpatient units, including critical care. According to the Human Resources Department, there were approximately 350 RNs working in the inpatient setting (personal communication, May 2012). The desired response rate was one third of RNs working on inpatient units.

\section{Site}

The site for the research was the Miriam Hospital (TMH), a 247-bed academic tertiary care hospital in Providence, Rhode Island. TMH has a long-standing history of encouraging annual influenza vaccination, offering vaccine free of charge to any employee. In recent years, mobile vaccination carts and a policy of active declination have been instituted. Maria Ducharme, Chief Nursing Officer (CNO), and Karen Joost, 
Director of Inpatient Nursing, provided permission to conduct the project (personal communication, July 19, 2012).

\section{Measurement}

Nurses' perception of mandated influenza vaccination was measured by a researcher developed survey. After reviewing the literature, the graduate student identified some common questions used in surveys regarding this topic. Because mandatory vaccination is a relatively new possibility, questions used in prior research were modified and some new questions were constructed based on the literature and professional nursing experience. The survey was pilot tested with 10 nurses enrolled in the Rhode Island College Master's in Nursing program and also included some nursing faculty. The survey was modified based on feedback provided.

The final survey (Appendix A) included basic demographic information, such as age, sex, education, whether or not the subject was involved in direct patient contact, and number of years as a nurse. The 10-item survey focused on whether or not participants agreed with mandatory influenza, and employed a Likert response scale in items 6 through 12. Most items were scored positively, including questions 6, 8, 9 and 10 (strongly agree $=5$, and strongly disagree $=1$ ). Two items, 7 and 11 were scored negatively ( strongly agree $=1$ and strongly disagree $=5$ ). Finally, an open-ended question that asked participants why they agreed or did not agree with the mandate was included.

\section{Procedures and Time Line}

Institutional Review Board (IRB) approval was obtained from both the RIC IRB 
and Lifespan IRB determined that the project was exempt. Based on nurses' feedback, the decision was made to make the surveys available to nurses in break rooms or on units for best access. After informing the CNO and Inpatient Nursing Directory of IRB approval, the primary researcher emailed unit managers and assistant unit managers to inform them that surveys would be delivered to the nursing unit and to obtain their feedback about a specific suggested locale. An IRB approved stamped informational letter (Appendix B) was placed with survey materials (Appendix A) in an envelope in a well-visited area of each unit, generally in break rooms. The informational letter described the purpose of the study, what it involved, and requested that staff not include their names on the survey. It also emphasized the voluntary nature of the study and that anonymity would be assured. The email address for the primary researcher was provided on the informational letter in the event that any questions or concerns arose. An IRB approved stamped flyer (Appendix C) to draw nursing staffs' attention to the opportunity to participate in the survey was placed on the front of the envelope containing the surveys and informational letter envelope. No emails directing questions to the researcher were received throughout the process.

Nurses indicated informed consent by completing and submitting the survey. A sealed drop box was provided on each unit for nurses to deposit completed surveys. Data collection occurred from January 7, 2013 until February 20, 2013 and the researcher collected surveys weekly from the units.

\section{Data Analysis}

Basic descriptive statistics were used to analyze the demographic data. Mean 
scores were calculated and compared for all survey questions and the open-ended question was analyzed for themes. Next, results will be presented. 


\section{Results}

Demographic data of survey participants is illustrated in Table 1.

Table 1.

Demographic Data of Participants $(N=130)$

\begin{tabular}{|c|c|c|c|}
\hline $\begin{array}{l}\text { Variable/ Question } \\
\text { Number }\end{array}$ & $\#$ & $\%$ & \# Missing \\
\hline 1. $\begin{array}{l}\mathrm{Sex} \\
\mathrm{N}=128\end{array}$ & $\begin{array}{l}\text { \# Male: } 8 \\
\text { \# Female: } 120\end{array}$ & $\begin{array}{l}\text { Male: } 6.25 \% \\
\text { Female: } 93.75 \%\end{array}$ & 2 \\
\hline $\begin{array}{ll}\text { 2. } & \text { Age } \\
\mathrm{N}=125\end{array}$ & $\begin{array}{l}20-30: 36 \\
31-40: 37 \\
41-50: 35 \\
51-60: 16 \\
61-70: 1\end{array}$ & $\begin{array}{l}20-30: 28.8 \% \\
31-40: 29.6 \% \\
41-50: 28 \% \\
51-60: 12.8 \% \\
61-70: 0.8 \%\end{array}$ & 5 \\
\hline $\begin{array}{l}\text { 3. Education } \\
\mathrm{N}=124\end{array}$ & $\begin{array}{l}\text { Diploma: } 1 \\
\text { Associate's: } 25 \\
\text { Bachelor's: } 90 \\
\text { Master's: } 7 \\
\text { Doctoral: } 1 \\
\end{array}$ & $\begin{array}{l}\text { Diploma: } 0.81 \% \\
\text { Associate's: } 20.16 \% \\
\text { Bachelor's: } 72.58 \% \\
\text { Master's: } 5.65 \% \\
\text { Doctoral: } 0.81 \% \\
\end{array}$ & 6 \\
\hline 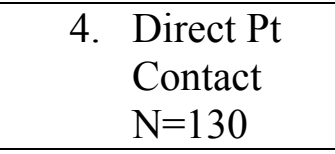 & $\begin{array}{l}\text { Yes: } 124 \\
\text { No: } 60\end{array}$ & $\begin{array}{l}\text { Yes: } 95.38 \% \\
\text { No: } 4.62 \%\end{array}$ & 0 \\
\hline $\begin{array}{l}\text { 5. Years as an } \\
\mathrm{RN} \\
\mathrm{N}=128\end{array}$ & $\begin{array}{l}0-10: 74 \\
11-20: 33 \\
21-30: 14 \\
31-40: 7 \\
41-50: 0\end{array}$ & $\begin{array}{l}0-10: 57.81 \% \\
11-20: 25.78 \% \\
21-30: 10.94 \% \\
31-40: 5.47 \% \\
41-50: 0 \%\end{array}$ & 2 \\
\hline
\end{tabular}

The majority of the nurses were female (93.75\%), and $86.4 \%$ were under the age

of 50. Percentage of nurses in the 20-30, 30-40, and 40-50 ranges were about equally distributed. The majority (72.5\%) had earned a bachelor's degree, and $57.81 \%$ had worked as a nurse for less than 10 years. The overwhelming majority of nurses $(95.38 \%)$ reported that they were in positions with direct patient contact. 
Table 2 presents questions 6 through 11, as well as the mean response of the participants.

Table 2.

\section{Selected Survey Questions and Mean Scores}

\begin{tabular}{|l|l|}
\hline Question \# & Mean Response \\
\hline $\begin{array}{l}\text { *6. Healthcare workers should be mandated to get the influenza } \\
\text { vaccine unless they have a medical exemption. }\end{array}$ & 2.14 \\
\hline $\begin{array}{l}* * 7 . \text { I would only receive the influenza vaccine if it were } \\
\text { mandated. }\end{array}$ & 3.485 \\
\hline $\begin{array}{l}\text { *8. I think a vaccine policy requiring influenza vaccination for all } \\
\text { healthcare workers is fair. }\end{array}$ & 2.177 \\
\hline $\begin{array}{l}\text { *9. Hospital policy requiring influenza vaccination keeps me from } \\
\text { getting influenza. }\end{array}$ & 2.07 \\
\hline $\begin{array}{l}\text { *10. Hospital policy requiring influenza vaccination keeps my } \\
\text { patients from getting influenza. }\end{array}$ & 2.307 \\
\hline$* * 11$ Hospital policy puts too much pressure on staff. & 2.252 \\
\hline
\end{tabular}

$*$ Strongly agree $=5$, strongly disagree $=1 ; * *$ Strongly agree $=1$, strongly disagree $=5$

As can be seen, most of the nurses tended to disagree that healthcare workers should be mandated to get the influenza immunization (mean 2.14), and tended to disagree that a vaccine policy requiring mandatory vaccination was fair (mean 2.177). They also tended to disagree that hospital policy requiring influenza vaccination keeps them from getting influenza (mean 2.07) or keeps their patients from getting influenza (mean 2.307). They agreed that hospital policy puts too much pressure on staff (mean 2.252). Overall, they tended to disagree that they would only receive the influenza vaccine if it were mandated (mean 3.485).

The open-ended responses were analyzed for themes, and the goal was to reach data saturation. Themes were compiled and summarized. Table 3 presents the most common themes heard in the open-ended responses. 
Table 3.

Open Ended Themes on Survey Question 12

\begin{tabular}{|l|l|}
\hline Themes: & Sample responses: \\
\hline $\begin{array}{l}\text { 1. Mandatory immunization is a violation } \\
\text { of personal choice/ rights. }\end{array}$ & $\begin{array}{l}\text {-"What you decide to put in your body is a } \\
\text { personal decision." } \\
\text {-"RNs should have the same rights as other } \\
\text { patients." } \\
\text {-"democracy = freedom of choice" }\end{array}$ \\
\hline $\begin{array}{l}\text { 2. Other measures are enough to prevent } \\
\text { the flu (handwashing/cough etiquette) }\end{array}$ & $\begin{array}{l}\text {-"I'm happily wearing my mask until April." } \\
\text {-Standard handwashing should prevent the spread } \\
\text { of influenza." }\end{array}$ \\
\hline $\begin{array}{l}\text { 3. Influenza vaccine is not effective, and } \\
\text { may not prevent transmission to patients. }\end{array}$ & $\begin{array}{l}\text {-"We can not eradicate the flu and common } \\
\text { cold." } \\
\text {-"Vaccines are not 100\% effective." } \\
\text {-"You are basically playing a guessing game and } \\
\text { this year is an example of how we guessed } \\
\text { wrong." }\end{array}$ \\
\hline 4. Side effects outweigh the benefits. & $\begin{array}{l}\text {-"I've been sick for days after receiving the } \\
\text { vaccine in the past." } \\
\text {-"I developed cellulitis that was extremely painful } \\
\text { from the injection." }\end{array}$ \\
\hline
\end{tabular}

The four identified themes reflected that nurses believed mandatory immunization violated personal choice and that other measures could be effectively used to prevent influenza. Nurses questioned the effectiveness of the vaccine, and some noted concerns about the side effects.

Next, summary and conclusions will be identified and discussed. 


\section{Summary and Conclusions}

Influenza is a significant cause of morbidity and mortality among hospitalized patients. Annual influenza vaccination is the most effective way to prevent getting influenza (CDC, 2011). Since 1981, the CDC has recommended annual influenza vaccination among healthcare workers (2011). Vaccination of all health care personnel is a specific focus of recommendation by the U.S. DHHS and other public health agencies and professional organizations. Health care provider vaccination rates vary annually, but are consistently below the Healthy People 2020 goal of achieving a $90 \%$ immunization rate (U.S. DHHS, 2012). Growing concern among government institutions and infectious disease organizations has led to consideration of mandating vaccination among healthcare workers. Despite multiple interventions to increase healthcare worker vaccination rates, rates remain low nationwide.

Many significant organizations support mandatory influenza vaccination for healthcare workers, including the Infectious Disease Society of America and the TJC. As a measure to increase vaccination rates to recommended levels, the state of RI considered mandatory vaccination during the 2012 flu season. Ultimately, mandatory vaccination did not pass at the statewide level. Nonetheless, RI revised its vaccination protocol to require mask wearing for unvaccinated staff during a period of flu epidemic. Due to tightened vaccination restrictions over the past several years, mandatory vaccination may become a reality in the near future in RI. Research about whether or not nursing personnel agree with and will support this mandate is limited. In a state that has never mandated influenza vaccination before, it is important to know the barriers, fears, and opinions from RNs, 
both to defray litigation and to gain the support of staff. The purpose of this project was to examine the perception of nursing staff toward mandated vaccine at a hospital in RI. Review of literature focused on one group of studies that examined barriers against and motivators for vaccination. Common barriers included fear of side effects, lack of a feeling of risk for influenza, concerns about safety and efficacy, time constraints, and lack of knowledge. Motivators for vaccination included having a mandatory policy, occupational health encouragement, on-site access, and protection from influenza. Another group of studies focused on the response of vaccination rate to various interventions, including declination programs, leadership support, educational forums, champion immunization nurses, and increased publicity, including an influenza website, a screen saver, emails and phone messages. Most of these studies showed a statistically significant increase in vaccination rates as a result of the interventions. Studies did not focus primarily on nurses, and other interventions were implemented at the same time, making it difficult to attribute causation to the interventions. Also, vaccination rates still did not increase to recommended levels.

Another pair of studies focused on the results of mandatory vaccination policies, which had been implemented in a tertiary care medical center in Seattle, Washington. The vaccination rate increased dramatically and met recommended levels. However, commentary on the article delineated the complexity of mandatory immunization, including fighting with the nurses' union, money spent in arbitration, and staff members leaving, either voluntarily or through termination.

The final group of studies looked at the perception of nurses toward mandatory 
influenza vaccination. Some of these studies were qualitative. One study found that while most nurses agreed that they would comply with mandatory vaccination, they were not in favor of the idea. Most nurses agreed with mandatory vaccination or a declination statement, but that truly does not represent mandatory vaccination, since they could decline for any reason. Another study found that most nurses agreed that the hospital should mandate vaccination, except in cases of medical exemption. Because the literature review found a gap, with studies focused primarily on nurses lacking, this study examined the perception of nursing staff toward mandatory influenza immunization at a hospital in RI, where mandatory vaccination was considered in 2012.

The study design was guided by the Social Ecological Model of Health (Bronfenbrenner, 1979; CDC, 2009). Study participants including RNs employed in inpatient units at $\mathrm{TMH}$, regardless of shift, hours worked or care area. The site was the Miriam Hospital, a 247-bed tertiary care hospital in Providence, RI. Nurses' perception of mandatory vaccination was measured by a survey developed by the researcher including both open and closed-ended questions. The survey included basic demographic information, such as age, sex, education, and number of years as a nurse. Nurses indicated informed consent by completing and submitting the survey.

The majority of the nurse respondents were female, less than 50, had a bachelor's degree, and had worked as a nurse for less than 10 years. Most of the nurses tended to disagree that healthcare workers should be mandated to get the influenza immunization; a vaccine policy requiring mandatory vaccination was fair; hospital policy requiring influenza vaccination keeps them from getting influenza or keeps their patients from 
getting influenza. The participants tended to agree that hospital policy puts too much pressure on staff. However, they tended to disagree that they would only receive the influenza vaccine if it were mandated. This was surprising, given that nurses had strongly disagreed with mandatory vaccination (mean 2.14). In review, this finding was similar to a study examining a hospital that employed mandatory vaccination, where they found that nurses in the union fought against the mandatory policy, but most still chose to get the vaccine nonetheless (Rakita, Hagar, Crome, \& Lammert, 2010).

Responses to the open-ended question of the survey led to four common themes. The first and most prevalent theme was the idea that mandatory immunization is a violation of personal choice and rights. Although most nurses denied that they would only get the vaccine if forced, this theme spoke directly to the idea that nurses did not agree with mandatory vaccination. The second theme was that other measures, such as proper hand washing and cough etiquette, were enough to prevent the flu. The efficacy of the vaccine was also questioned. Finally, concerns about side effects of the vaccine were seen as riskier than the benefits derived from the vaccine.

The limitations of the study included that findings were derived primarily from a self-reported survey. The sample included $130 \mathrm{RNs}$, employed at one institution. Limited demographic data were collected, and data related to ethnicity was not gathered. Further studies to examine the potential impact of ethnicity on perceptions related to mandatory vaccination is indicated. This location was seen as important because mandatory influenza immunization was strongly considered in RI that season.

Based on the literature review, it is evident that mandatory vaccination is the only 
effective measure to raise healthcare worker vaccination rate to recommended levels. RI just tightened restrictions to require masking for unvaccinated employees during a period of designated flu outbreak, and based on the review, this measure likely won't lead to vaccination at target levels. There are also many groups who don't agree with mandatory vaccination, including union groups. Due to the large cost to enforce mandatory vaccination policies demonstrated in prior research, it is important to determine the concerns of those affected by these changes.

As a result of this study, it is evident that nurses at TMH do not agree with mandatory vaccination. In a state that was considering mandatory vaccination statewide, this is an important consideration before implementation of this potential measure.

Next, recommendations and implications for advanced practice nursing will be presented. 


\section{Recommendations and Implications}

As evident from the results of this study, many of the nurses displayed doubts about the efficacy of the vaccine. Recent data from the CDC (2013a) showed that the vaccine efficacy for the 2012-2013 flu season, based on avoidance of seeking medical care due to flu illness, was $56 \%$ for all age groups (95\% confidence interval: $47-63 \%$ ). This efficacy varied across age groups and across different flu viruses, with much less efficacy in people aged 65 and older. When looking at the efficacy of specific flu viruses, effectiveness against flu A (H3N2) was estimated to be $47 \%$ for all ages, and this was the main virus of the season (CDC, 2013a). This is likely why nursing staff expressed such skepticism about the efficacy of the vaccine. Is this efficacy sufficient to mandate vaccination for all nurses? In consideration of this question, it's important to recognize that the CDC data analysis only accounted for avoidance of physician visits, not for time lost from work, flu-related illness, hospitalization and death.

Some nurses also reported that they didn't mind wearing a mask throughout he flu season. Is this measure sufficient to protect against unvaccinated healthcare workers? Is it too complex to enforce mask wearing of staff? Can the enforcement of mask wearing be improved so as to avoid mandatory immunization? Clearly, many questions remain and further research and policy development is needed.

Despite intensive efforts and expenditure of significant costs and time, education, promotion efforts and campaigns had only limited success among health care workers. The CDC (2013b) is currently using a social marketing approach to health communications, including mass media and personal messages to increase awareness of 
products such as immunization, benefits, and personal motivation to seek health behaviors. This method could be useful in planning influenza vaccine campaigns for high-risk segments of populations, such as healthcare workers.

If considering mandating health care worker vaccination again in the future, health care organizations must keep vaccination an informed process, with consideration for medical exemption. Implementation must also address fears and misconceptions of all members of the healthcare team about vaccine safety, and social marketing could help to dispel rumors and fears. The impact of social marketing on increasing vaccination rates among healthcare workers is a potential field for further research. Looking at the prevention of lost work and flu-related illness specific to healthcare workers/ nurses may be another potential area for future research.

Despite improvements in education, awareness of symptoms, and respiratory hygiene precautions, influenza vaccination rates still remain unacceptably low amongst health care workers. Many staff nurses still seem to disagree that mandatory influenza is necessary, and doubt the benefits and safety of the vaccine. Mandatory health care worker vaccination programs result in high vaccination rates, as seen in mandates for other vaccines, including measles-mumps-rubella and hepatitis B vaccines. Given that there is a safe, low-cost, effective method to prevent transmission, health care organizations and public health decision makers have an obligation to take action if public health is jeopardized. A recent influenza epidemic this season provides an opportunity for policymakers to reconsider the benefits of mandating influenza vaccination for healthcare workers, including enhancing patient safety. These policies 
must be developed and instituted at statewide levels, not institution specific, because vaccinating healthcare workers promotes public health. Also, implementation of a statewide mandate would shift litigation away from individual institutions.

The right of individuals to refuse medical treatment has been long recognized by healthcare workers, and U.S. labor laws recognize the right of individuals to form unions and collectively bargain over the conditions of employment. Before considering mandatory vaccination again, vaccine availability must be considered. Several interdisciplinary professional and government organizations have indicated support of mandatory influenza immunization as discussed in the literature review. Typically, laws that require vaccination translate national recommendations into practice on a state level, as in the example of school attendance requirements to protect children against vaccinerelated disease. Examination of school vaccination laws provides a context for understanding the benefits of mandatory vaccination in relation to healthcare workforce. This would be a similar example of using national recommendations to create state policy. In addition, progress must be made on changing the wording of future nursing union contracts, which have prevented mandatory vaccination in the past and cost significant funds in arbitration.

Given the questionable rate of vaccine efficacy, concerns of nursing staff, potential areas for litigation, including nursing union contracts, and a possible working solution with the requirement for mask wearing, it will be extremely complex to require immunization on a statewide level at this point. Despite the fact that mandatory immunization has proven to be the best way to increase vaccination rates, more research 
and policy changes must occur before this is considered a feasible solution.

Advanced practice registered nurses (APRNs) can play a role both by supporting vaccination for healthcare workers, advocating vaccination for their patients through extensive education, and advocating for change of policy. APRNs can play a role by being involved on councils that discuss and recommend policy changes and by assisting in the drafting of legislation. APRNs have an obligation in regard to clinical prevention and public health, and vaccination of healthcare workers falls into this category. Nursing education, including associate and bachelor's degree programs, should have content on influenza vaccination, and APRNs may be involved in developing or teaching this content. The focus of immunization must change from that of personal protection to a public safety initiative, much as we improve public safety in many other domains. In order to accomplish that, the needs of the increasing diverse members of society must be considered and addressed. 


\section{References}

Abramson, Z. H., Avni, O., Levi, O., \& Miskin, I. N. (2010). Randomized trial of a program to increase staff influenza vaccination in primary care clinics. Annals of Family Medicine, 8(4), 293-298.

American Nurses Association. (2010, September 9). ANA urges nurses to get the seasonal influenza vaccine. Retrieved from http://www.nursingworld.org/ANAUrges-RNs-Get-Seasonal-Influenza-Vaccination

Bronfenbrenner, Urie. The Ecology of Human Development. Cambridge: Harvard University Press, 1979. Print.

Cadena, J., Prigmore, T., Bowling, J., Ayala, B. A., Kirkman, L., Parekh, A., Scepanski, T., \& Patterson, J. E. (2011). Improving influenza vaccination of healthcare workers by means of quality improvement tools. Infection Control and Hospital Epidemiology, 32(6), 616-618.

Centers for Disease Control and Prevention. (2009, September 9). The social ecological model: A framework for prevention. Retrieved from http://www.cdc.gov/ViolencePrevention/overview/social-ecologicalmodel.html

Centers for Disease Control and Prevention. (2011, August 26). Prevention and control of influenza vaccines: Recommendations of the advisory committee on immunization practices. Morbidity and Mortality Weekly, 60(33), 1128-1132.

Centers for Disease Control and Prevention. (2013a, March 15). What you should know for the 2012-2013 influenza season. Retrieved from http://www.cdc.gov/flu/about/season/flu-season-2012-2013.htm 
Centers for Disease Control and Prevention. (2013b, April 11). Gateway to health communication and social marketing practice. Retrieved from http://www.cdc.gov/healthcommunication/

Christini, A. B., Shutt, K. A., \& Byers, K. E. (2007). Influenza vaccination rates and motivators among healthcare worker groups. Infection Control and Hospital Epidemiology, 28(2), 171-177.

Daugherty, E. L., Speck, K. A., Rand, C. S., \& Perl, T. M. (2011). Perceptions an influence of a hospital influenza vaccination policy. Infection Control and Hospital Epidemiology, 32(5), 449-455.

Hirsh, P., Hodgson, M., \& Davey, V. (2011). Seasonal influenza vaccination of healthcare employees: Results of a 4 year campaign. Infection Control and Hospital Epidemiology, 32(5), 444-448.

Immunization Action Coalition. (2012, April 20). Honor roll for patient safety. Retrieved from http://www.immunize.org/honor-roll/

Marshall, R. J., Tetu-Mouradjian, L. M., \& Fulton, J. P. (2010). Increasing annual influenza vaccinations among healthcare workers in Rhode Island: A social marketing approach. Medicine \& Health, 93(9), 271-278.

McLeroy, K. R., Bibeau, D., Steckler, A., \& Glanz, K. (1988). An ecological perspective on health promotion programs. Health Education Quarterly, 15(4), 351-377.

Mouzoon, M. E., Munoz, F. M., Greisinger, A. J., Brehm, B. J., Wehmanen, O. A., Smith, F. A., Markee, J. A., \& Glezen, W. P. (2010). Improving influenza immunization in pregnant women and healthcare workers. The American Journal 
of Managed Care, 16(3), 209-216.

Myers, A. L., Lantos, J., \& Douville, L. (2010). Healthcare worker knowledge and attitudes regarding influenza immunization and childhood vaccination. Infection Control and Hospital Epidemiology, 31(6), 643-646.

Ofstead, C. L., Tucker, S. J., Beebe, T. J., \& Poland, G. A. (2008). Influenza vaccination among registered nurses: Information receipt, knowledge, and decision making at an institution with a multifaceted education program. Infection Control and Hospital Epidemiology, 29(2), 99-106.

Poland, G. A., Ofstead, C. L., \& Tucker, S. J. (2008). Receptivity to mandatory influenza policies for healthcare workers among registered nurses working on inpatient units. Infection Control and Hospital Epidemiology, 29(2), 170-173.

Polgreen, P. M., Septimus, E. J., Parry, M. F., Beekman, S. E., Cavanaugh, J. E., Srinivasan, A., \& Talbot, T. R. (2008). Relationship of influenza vaccination declination statements and influenza vaccination rates for healthcare workers in 22 U. S. hospitals. Infection Control and Hospital Epidemiology, 29(5), 675-677.

Rakita, R. M., Hagar, B. A., Crome, P., \& Lammert, J. K. (2010). Mandatory influenza vaccination of healthcare workers: A 5-year study. Infection Control and Hospital Epidemiology, 31(9), 881-888.

Rebmann, T., Wright, K. S., Anthony, J., Knaup, R. C., \& Peters, E. B. (2012). Seasonal influenza vaccine compliance among hospital-based and non hospital-based healthcare workers. Infection Control and Hospital Epidemiology, 33(3), 243-249. Rhode Island Department of Health (2012). Immunization Information for Healthcare 
Workers. Retrieved from

http://www.health.ri.gov/immunization/for/healthcareworkers/

Rhudy, L. M., Tucker, S. J., Ofstead, C. L, \& Poland, G. A. (2010). Personal choice or evidence based nursing intervention: Nurses' decision-making about influenza vaccination. Worldviews on Evidence-Based Nursing, 7(2), 111-120.

Ribner, B. S., Hall, C., Steinberg, J. P., Bornstein, W. A., Chakkalakal, R., Emamifar, A., Eichel, I., Lee, P. C., Castellano, P. Z., \& Grossman, G. D. (2008). Use of a mandatory declination form in a program for influenza vaccination of healthcare workers. Infection Control and Hospital Epidemiology, 29(4), 302-308.

Stokols, D. (1996). Translating social ecological theory into guidelines for community health promotion. American Journal of Health Promotion, 10(4), 282-298.

Talbot, T. R., \& Schaffner, W. (2010). On being the first: Virginia Mason Medical Center and mandatory influenza vaccination of healthcare workers. Infection Control and Hospital Epidemiology, 31(9), 889-892.

The College of Physicians of Philadelphia (2013). Timelines: History of Vaccines. Retrieved from http://www.historyofvaccines.org/content/timelines/all

The Joint Commission. (2006). New infection control requirement for offering influenza vaccination to staff and licensed independent practitioners. Joint Commission Perspectives, 26(6), 10-11.

The National Vaccine Advisory Committee (2012, February 8). Recommendations on strategies to achieve the healthy people 2020 annual influenza vaccine coverage goal for health care personnel. Retrieved from 
www.hhs.gov/nvpo/nvac/influenza_subgroup_final_report.pdf

Toronto, C. E., \& Mullaney, S. M. (2010). Registered nurses and influenza vaccination: An integrative review. American Association of Occupational Health Nurses, $58(11), 462-471$.

U. S. Department of Health and Human Services. (2012, July 26). Healthy people 2020 topics and objectives. Retrieved from http://www.healthypeople.gov/2020/topicsobjectives2020/objectiveslist.aspx?topi $\mathrm{cId}=23$ 


\section{Appendix A}

Survey

Please circle the best answer for each question.

1. Sex?

(MALE)

(FEMALE)

2. Age?

(20-30)

(31-40)

$(41-50) \quad(51-60)$

$(61-70)$

3. Highest level of education?

(Diploma) (Associate's Degree) (Bachelor's Degree) (Master's Degree) (Doctoral Degree)

4. Involved in Direct Patient Contact?

(YES)

(NO)

5. Number of Years as a Registered Nurse?

$(21-30)$

$(31-40)$

$(41-50)$

6. Healthcare workers should be mandated to get influenza vaccine unless they have a medical exemption.

(strongly agree) $\quad$ (agree) $\quad$ (don't know) (disagree) $\quad$ (strongly disagree)

7. I would only receive the influenza vaccination if it was mandated.

(strongly agree) $\quad$ (agree) $\quad$ (don't know) (disagree) $\quad$ (strongly disagree)

8. I think a vaccine policy requiring influenza vaccination for all healthcare workers is

fair.

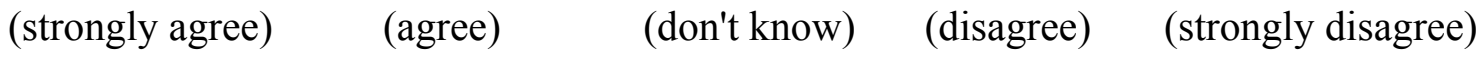


9. Hospital policy requiring influenza vaccination keeps me from getting influenza.

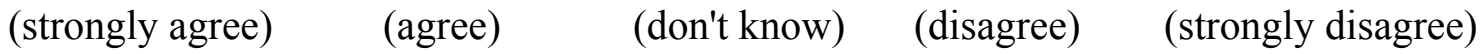
10. Hospital policy requiring influenza vaccination keeps my patients from getting influenza.

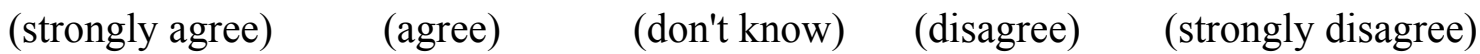
11. Hospital policy puts too much pressure on staff.

(strongly agree) $\quad$ (agree) $\quad$ (don't know) (disagree) $\quad$ (strongly disagree) 12. Please provide a reason for why you agree or disagree with mandatory vaccination.

Appendix B 
I would like to inform you of a research study that you may be eligible to participate in. You are a possible participant in this study if you are a Registered Nurse on an inpatient unit at the Miriam Hospital. The purpose of this study is to examine the perception of nursing staff toward mandated influenza vaccine.

This study will be available until February 2013. The expected duration of your participation is about five minutes. It involves completing a survey that is included in this packet, and submitting the survey in the drop box. You may choose not to answer any question(s) and are free to stop at any time. Participation is voluntary. Refusal to participate will involve no penalty or loss of benefits. Your decision to participate or not will not impact your work at the Miriam Hospital.

There are no known risks or discomforts to the participant. You may not directly benefit from participation in this research; however, your answers will help us to understand the perception of nursing staff toward the mandate. Confidentiality of responses will be maintained, as you are asked not to include your name on the survey. For questions about the research, you may contact Meghan Nightingale at meghan.nightingale@gmail.com. You may also contact Dr. Christine Marco, chair of Rhode Island College Institutional Review Board, by email at IRB@ric.edu or by phone at 401-456-8598, or the Miriam Hospital Institutional Review Board by phone, at 401444-3527 for any questions, including information about your rights as a research participant.

There will be no compensation for your participation in this survey. All inpatient nurses at the Miriam Hospital will be asked to consider completing this survey. 
Thank you for considering participation in this study. Consent to participate will be implied based on completion and return of the survey.

Meghan Nightingale, BSN, RN-BC

Rhode Island College Acute Care Nurse Practitioner student

Appendix C

Flyer 


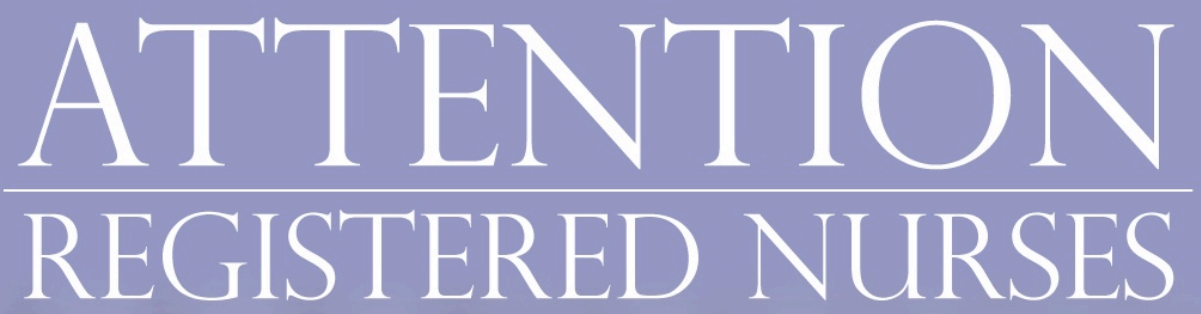

TMH Approval: 10/17/2012

IRB Accepted: 11/8/2012

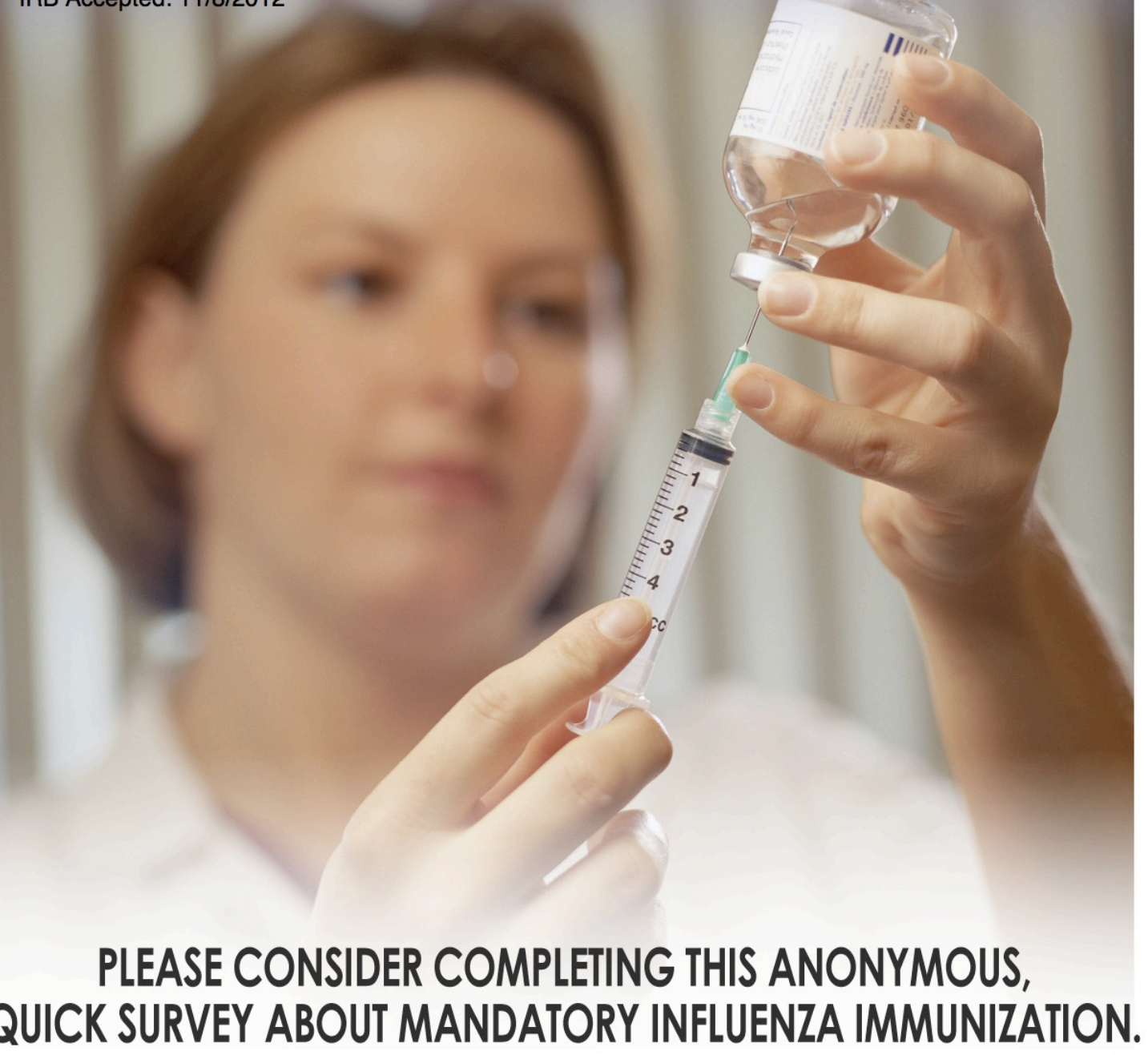

Thank You!

Appendix D

Flyer 2 


\title{
ATTENTION REGISTERED NURSES
}

TMH Approval: 10/17/2012

IRB Accepted: 11/8/2012

\section{PLEASE CONSIDER COMPLETING THIS ANONYMOUS,} QUICK SURVEY ABOUT MANDATORY INFLUENZA IMMUNIZATION.

\author{
Thank You!
}


